\title{
Estrategias de enseñanza para la calidad del aprendizaje de los alumnos de escuelas rurales de Molango
}

Cabello Téllez Uriel Savad

Hernández Hernández Magdalena

Martínez Aldás Samantha

Zepeda Romero Cecilia Yanet

\section{Introducción}

Hoy en día en México la situación educativa se encuentra en crisis porque no se tiene una visión clara de lo que se quiere poner en marcha y mucho menos un espíritu emprendedor para que sus ideales puedan ser reconocidas y favorables para el ámbito educativo.

Cuando se presentan situaciones difíciles, se responsabiliza a los docentes, sin saber que no sólo es labor de ellos, sino también de las familias de los alumnos, porque es desde ahí donde se aprenden valores y virtudes, mucho antes de ingresar a la escuela.

Los profesores de educación pública cuentan con un sindicato que los apoya y algunos de ellos se inmiscuyen en asuntos políticos. Desafortunadamente, cuando la SEP no les ayuda o garantiza acciones que les favorezcan, suspenden actividades y dejan sin clases a los niños.

La educación rural es muy diferente a la educación urbana, puesto que no cuenta con recursos y docentes realmente capacitados para la aplicación del Proceso-EnseñanzaAprendizaje (PEA), es decir, que carecen de formación académica para educar a un niño, por ejemplo a estudiantes egresados de preparatoria se les asignan grupos multigrados

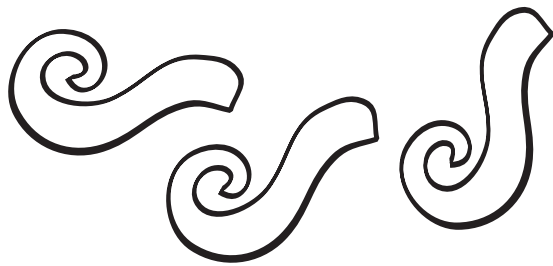

por la carencia de recursos humanos y se les paga sin la preparación previa para ejercer como docente.

Inclusive, algunos profesores mencionan, que solo son "profesores", porque "no les quedó otro remedio más que estudiar esa carrera", entonces, ¿dónde está la vocación docente? Los profesores deben estar en constante actualización para tener y brindar una mejor educación.

La sociedad debe responsabilizarse de los niños, sabiendo que todos tienen un fin en común, se busca la seguridad y la integridad de cada uno de ellos, pero, ¿cómo encontrar la visión, la integridad y la forma de vida de las personas si nos olvidamos que la principal base es la educación? Sin duda alguna, la calidad de vida de muchos estudiantes afecta la misma en la escuela. Nos corresponde hacer una investigación a fondo de manera presencial en lugares rurales donde las condiciones son muy distintas a las urbanas y las carencias que existen son notorias y de suma importancia, para que en un futuro como educadores, se puedan abrir caminos y ayudar a realizar proyectos desde diversos enfoques para no quedarse sólo con una visión mínima de la educación.

1 Octavo semestre de la Licenciatura en Ciencias de la Educación. (scappino_net@hotmail.com) 2 Octavo semestre de la Licenciatura en Ciencias de la Educación. (magdabeatle@hotmail.com) 3 Octavo semestre de la Licenciatura en Ciencias de la Educación. (samy20_91@hotmail.com)

4 Octavo semestre de la Licenciatura en Ciencias de la Educación. (ceciyanet_rv@hotmail.com) 


\section{Problema de investigación}

Indagaremos, cómo se aplican las estrategias de enseñanza para la calidad del aprendizaje de los estudiantes de escuelas rurales en Molango, específicamente de educación primaria del sector público.

\section{Preguntas de investigación}

1. ¿Qué tipos de estrategias de enseñanza utilizan los docentes en las escuelas rurales de Molango y sus comunidades circunvecinas?

2. ¿Las estrategias que se aplican se enfocan en el aprendizaje significativo del alumno?

\section{Objetivo general}

Conocer e identificar las estrategias de enseñanza que los docentes utilizan durante el PEA para los conocimientos adquiridos por los estudiantes, y de esta manera generar propuestas alternativas de mejora en los métodos de enseñanza utilizados por los docentes para el aprendizaje significativo.

\section{Objetivos específicos}

1. Conocer las estrategias que los docentes utilizan para enseñar a los estudiantes en las escuelas rurales de Molango.

2. Identificar cómo los docentes aplican sus estrategias en el PEA.

3. Identificar cómo se promueven las estrategias de enseñanza dentro del salón de clases.

\section{Justificación}

El interés de este tema surge a partir de los aspectos que hemos ido observando en la educación rural en las diferentes comunidades, lo que coadyuve a potencializar en ello cambios en el proceso educativo.

Esta investigación se inserta con base en el
Proyecto Educativo Regional Lasallista (PERLA), el cual se enfoca en mejorar las condiciones de vida de personas desfavorecidas, por medio de la implementación de diversos proyectos de acuerdo a las cinco urgencias planteadas en ella:

Democratización del conocimiento, Nuevas tecnologías, Una educación en y desde la promoción del desarrollo humano sostenible, Una educación en y desde el respeto a los derechos humanos y Educación de calidad, siendo esta última la elegida para realizar el proyecto de investigación en el municipio de Molango, Hgo.

\section{Marco histórico}

La educación en Molango ha sufrido constantes cambios a lo largo de las décadas. Incluso los profesores de ahora no cuentan con la vocación que los profesores contaban hace tiempo, nos referimos a que ahora ya no son tan comprometidos con su trabajo ni con los niños. No se trata de dejar en mal a los docentes, esto se comenta para que en futuro la educación pueda mejorar. Los educadores de antes le ponían más empeño al aprendizaje del alumno, hacían las clases divertidas con juegos que en ese entonces existían pero sobre todo a los alumnos los veían como hijos. Antes los profesores le dedicaban más tiempo a aquellos alumnos que les costaba trabajo aprender, incluso tenían técnicas para un mejor apoyo en el aprendizaje del niño. La educación era tradicionalista, en algunas instituciones lo sigue siendo. En ese entonces la educación era preescolar, primaria, secundaria y de esta última pasaban directo a la carrera.

A finales del siglo XX estudiar en escuelas alrededor de Molango no era tan complicado porque en las escuelas se contaba con conocimientos suficientes para continuar con los estudios, las escuelas eran pequeñas, no había muchos alumnos, y como eran de bajos recursos no todos asistían a la escuela pues había quienes debían trabajar con sus familias. 


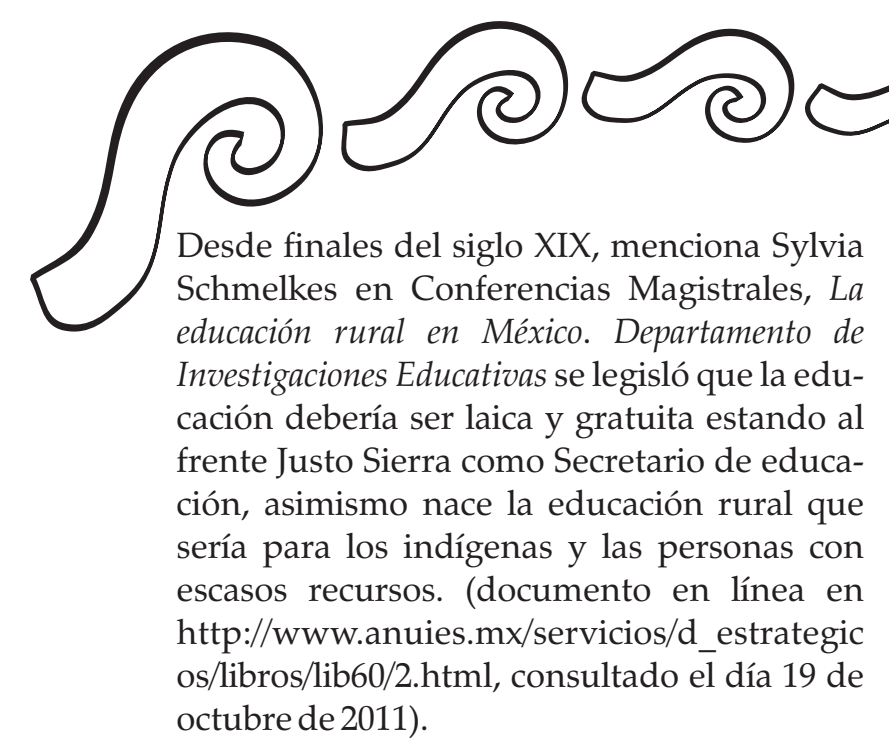

Con el paso del tiempo los profesores egresados de la Normal Superior o del Centro Regional de Educación Normal empezaron a aumentar, es por eso que el currículo de los profesores es predominante en la actualidad. Los profesores trataron de cambiar el método de enseñanza que se tenía en Molango, el método tradicionalista pero al parecer en algunas escuelas sigue siendo igual. Los profesores del siglo pasado eran muy queridos por el alumno, pues su forma de enseñar era única, ya que era más la vocación que tenían los profesores de antes. Incluso hay escuelas que los salones contienen nombres de profesores que fueron muy queridos por los alumnos, digo fueron porque la mayoría de ellos ya fallecieron, esos profesores tenían un modo de tratar a los niños de un modo particular. Los conocimientos que antes se brindaban a los alumnos eran significativos, hacían que los conocimientos quedaran muy claros para después llegar a ser excelentes profesionales. Sin embargo, cada quién decidía si quería seguir estudiando o dedicarse a otras cosas, como son: el campo, la albañilería, etc. (Martínez, 2011).

\section{Marco conceptual}

Una estrategia, de acuerdo con la Real Academia Española (tiene distintos significados

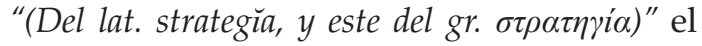
primero es"Arte de dirigir las operaciones militares"; nos ofrece un segundo concepto "Arte, traza para dirigir un asunto" y por último "En un proceso regulable, conjunto de las reglas que aseguran una decisión óptima en cada momento". A fin de lo investigado, las estrategias son las formas en las que un docente imparte sus clases en el Proceso de Enseñanza-Aprendizaje (PEA).

En cuanto a enseñanza, la RAE hace mención de diversos conceptos de los cuales se tomaron los siguientes: "Acción y efecto de enseñar", "Sistema y método de dar instrucción", "Ejemplo, acción o suceso que sirve de experiencia, enseñando o advirtiendo cómo se debe obrar en casos análogos", "Conjunto de conocimientos, principios, ideas, etc., que se enseñan a alguien". Enseñanza, para esta investigación es la acción de enseñar, son las experiencias que un docente regula en el PEA $\mathrm{y}$ en las que utiliza todos sus conocimientos, principios e ideas para ejecutar dicha actividad.

R A E, 2001, r e c u p e rado d e. http://buscon.rae.es/draeI/SrvltConsulta?TIP O_BUS $=3 \&$ LEMA=estrategia el 9 de septiembre de 2011)

(Real Academia Española (2001) en Diccionario de la Lengua Española, 22 $2^{a}$ ed. Recuperado de. http://buscon.rae.es/draeI/SrvltConsulta?TIP O_BUS=3\&LEMA=enseñanzael 9 de septiembre de 2011)

La calidad, es en la Real Academia Española de las raíces etimológicas "Del lat. qualitas, ătis, y este calco del gr. $\pi$ orótns", "Propiedad o conjunto de propiedades inherentes a algo, que permiten juzgar su valor", otra concepción de calidad es "Buena calidad, superioridad o excelencia.", "Condición o requisito que se pone en un contrato", "Importancia o gravedad de algo". Por otro lado, y desde una perspectiva más concreta la calidad educativa es la eficacia de las escuelas y de su gestión en los recursos educativos, esto de acuerdo a Mercedes Muñoz-Repiso, Jesús Cerdán, 


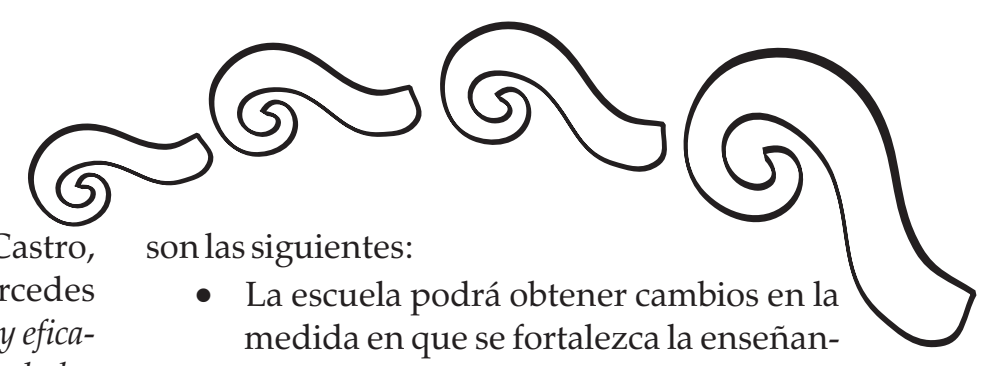

Javier Murillo, Juan Calzón, María Castro, Inmaculada Egido, Raquel García y Mercedes Lucio-Villegas en Calidad de la educación y eficacia de la escuela: Estudio sobre la gestión de los recursos educativos (1995). A efecto de la investigación la calidad, en términos educativos, es el cumplimento de los estándares que deben cubrir las escuelas y que le da una cualidad superior o de excelencia a los conocimientos que poseen los alumnos.

Si nos referimos ahora al aprendizaje, nos dice que "(De aprendiz)", es la "Acción y efecto de aprender algún arte, oficio u otra cosa", "Tiempo que en ello se emplea" y "Adquisición por la práctica de una conducta duradera". Aprendizaje, es entonces, lo que un alumno es capaz de adquirir, por medio de la práctica y el cambio de conductas, lo cual conlleva un tiempo determinado para cierto tipo de conocimientos.

En cuanto a escuelas rurales, la RAE dice que rural es (Del lat. rurāis, de rus, ruris, campo)."Perteneciente o relativo a la vida del campo y a sus labores" e "Inculto, tosco, apegado a cosas lugareñas", las escuelas en las que se realiza la investigación son rurales, es decir, se localizan en lugares donde la vida es campirana, apegada a sus circunstancias y tradiciones.

\section{Marco teórico}

Desde lo que plantea Schmelkes (2001) la perspectiva de fortalecer la escuela se descubren tres tendencias, no necesariamente contrapuestas, es más posiblemente complementarias, pero sí se difieren en énfasis, y en ocasiones conducen a decisiones antagónicas. Éstas za. La escuela tiene como cometido fundamental asegurar el aprendizaje, en ella, la enseñanza es la que lo permite. Es necesario que los docentes puedan enseñar de manera tal que los niños aprendan. El director, tiene que estimular, hacer posible y si es necesario, dirigir este proceso.

- La escuela se modificará en la medida en que se fortalezca su gestión. La institución escolar es clave para propiciar el clima necesario para que se dé la enseñanza y el aprendizaje. Se requiere de una cultura que favorezca el trabajo colegiado, el espíritu de innovación y de mejoramiento, la capacidad de visualizar conjuntamente una escuela distinta y de trabajar juntos para lograrla. De ello dependerá que los maestros se sientan a gusto y satisfechos, que se desarrollen profesionalmente y también que los niños vayan contentos a la escuela y prefieran estar ahí que en otro lado. Entonces lo que hay que fortalecer la escuela como tal, su ethos ${ }^{1}$.

- La escuela sufrirá cambios en la medida en que se fortalezca la comunidad a la que sirve. La comunidad tiene que ser capaz de saber qué esperar de la escuela. Tiene que poder exigirle un servicio de calidad. Debe estar dispuesta a poner lo que está de su parte para que ese servicio funcione adecuadamente.

En el fenómeno educativo y se han formulado diversas teorías acerca de cómo aprendemos y de qué manera debemos enseñar. Los planes y

1.Término antropológico que significa carácter común de comportamiento o forma de vida que adopta un grupo de individuos que pertenecen a una misma sociedad. (RAE, 2001,Diccionario de la Lengua Española, recuperado de: http://buscon.rae.es/draeI/SrvltConsulta?TIPO_BUS=3\&LEMA=calidad,el 9 de septiembre de 2011) la RAE (Real Academia Española (2001) Aprendizaje, en Diccionario de la Lengua Española, $22^{\mathrm{a}}$ ed. Recuperado de: http://buscon.rae.es/drael/SrvltConsulta?TIPO_BUS=3\&LEMA=aprendizaje el 9 de septiembre de 2011) RAE (Real Academia Española (2001) en Diccionario de la Lengua Española, 22 a ed. Recuperado de: http://buscon.rae.es/draeI/SrvltConsulta?TIPO_BUS=3\&LEMA=rural el 9 de septiembre de 2011) 


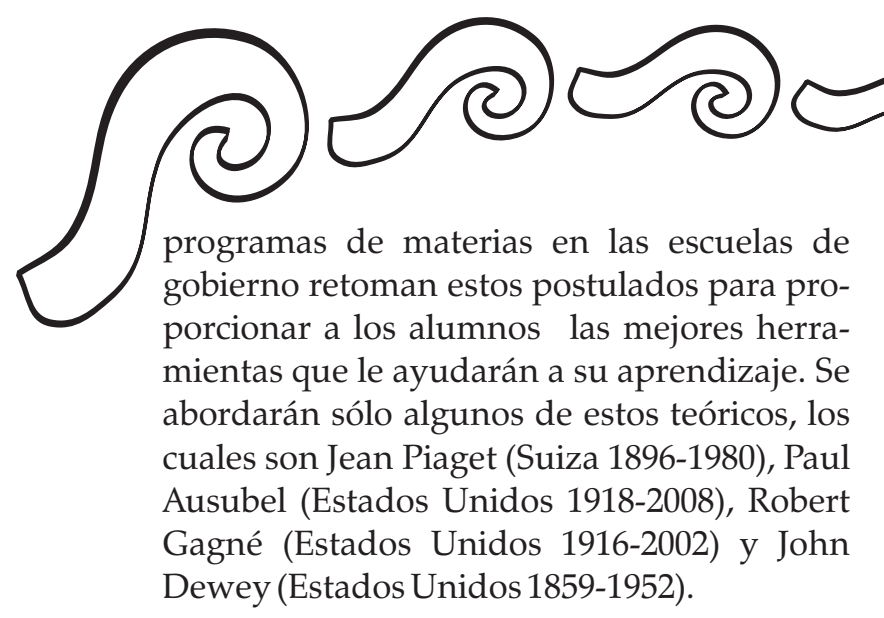

Bien menciona Jean Piaget:

$\mathrm{Al}$ abordar una tarea tan temeraria como la de querer resumir y, con mayor razón, intentar juzgar el desarrollo de la educación y la instrucción durante estos últimos treinta años, se llena uno de verdadero espanto ante la desproporción que subsiste hoy, tanto como en 1935, entre la inmensidad de los esfuezos realizados y la ausencia de una renovación fundamental de los métodos, de los programas, de la situación misma de los problemas y, en suma, de la pedagogía en su conjunto en tanto que disciplina directriz (Piaget, 2001:p.9).

Este fragmento lo escribió Piaget en 1935 y, ya desde entonces, menciona el autor, los esfuerzos por utilizar los métodos de enseñanza en las aulas e innovar en los mismos, era desproporcional. Entonces, si la comparamos con lo que vivimos en la actualidad dentro de las aulas mexicanas, conocemos y reconocemos que estamos en la misma situación de la cual Piaget hablaba desde hace más de 70 años. Es importante entonces innovar para satisfacer las necesidades de la población estudiantil y que la misma sociedad exige de ellos.

Para entender, los procesos de enseñanzaaprendizaje, se mencionan las teorías de algunos de los más reconocidos teóricos de la pedagogía. Con esto se pretende contextualizar acerca de algunos métodos utilizados en el PEA y que nos darán información para analizar, posteriormente, el PEA utilizado en las aulas de educación primaria en el municipio de Molango, Estado de Hidalgo.

Primeramente se aborda Piaget, quien en un principio fue biólogo y epistemólogo; es el quien desarrolló una teoría de la inteligencia humana; la teoría del desarrollo cognitivo. Piaget menciona otras cosas más acerca del desarrollo cognoscitivo. Simplemente, se abordará una parte de la teoría que tiene que ver con el conocimiento del ser humano a través de toda su vida, recordemos que Piaget se inclinaba más al desarrollo de la inteligencia en losniños que al de los jóvenes y la vida adulta.

Por otro parte, Paul Ausubel era un psicólogo y pedagogo estadounidense que propuso el aprendizaje significativo, en su libro Psicología educativa: un punto de vista cognoscitivo; Ausubel, Novak Y Hanesian (1983) mencionan que "El aprendizaje significativo comprende la adquisición de nuevos significados y, a la inversa, estos son producto del aprendizaje significativo. Esto es, el surgimiento de nuevos significados en el alumno refleja la consumación de un proceso de aprendizaje significativo" (Ausubel, 1983: 48).

De esta manera Ausubel da a entender que el aprendizaje significativo hace un presupuesto de que el alumno pone de manifiesto una actitud de aprendizaje significativo (disposición para relacionar sustancialmente el nuevo material con su estructura cognoscitiva), así como también, que el material que aprende es sustancialmente significativo para él (relacionable con su estructura de conocimiento sobre una base no arbitraria) (Ausubel, 1983: 48).

Lo que Ausubel propone es que los alumnos desarrollen la habilidad de relacionar significados previos con los nuevos. Es decir, que para la población infantil de Molango, los hechos, conceptos, procedimientos, valores y actitudes que se ensañarán deber estar relacionados básicamente con el contexto en el que viven y se desarrollan.

Cuando un alumno estructura de manera más eficaz sus conceptos y significados, tiene 


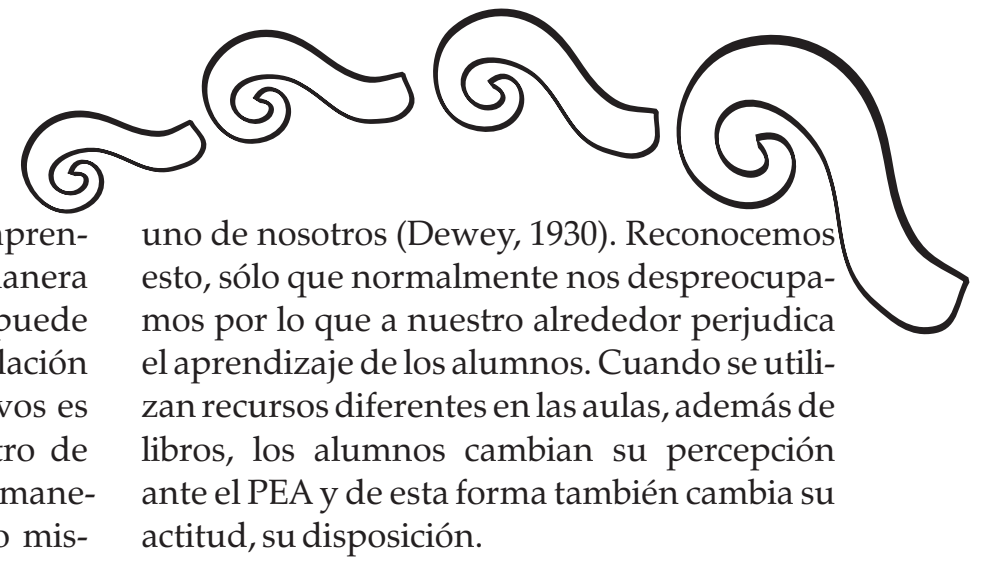

mayor oportunidad de comprender y aprender los nuevos conocimientos. De manera que, cuando sea necesario, el alumno puede adquirir mayor conocimiento si la relación entre sus conocimientos previos y nuevos es acertada. Cualquier desequilibrio dentro de esta relación de significados afectaría de manera importante el desarrollo del alumno mismo, dando como resultado alumnos que no comprenden el tema o hasta recursar alguna materia.

Otro autor que se menciona es el psicólogo y pedagogo estadounidense Gagné, en su obra La planificación de la enseñanza: sus principios menciona que la información que se les da a los estudiantes se les puede dar a través del oído, de forma verbal, o por los ojos con libros o ilustraciones. Con esto, damos por entendido que existen diversas herramientas que nos ayudan y nos permiten ofrecer la información con técnicas adecuadas al tema. Para elegir una herramienta o técnica al exponer un tema debemos considerar el mensaje que queremos dar, las personas a quien va dirigido y el mismo contexto donde se da la clase. En la misma obra nos dice que el alumno debe tener de manera clara sus aprendizajes previos, debe estar motivado y tener una actitud de confianza en aprender, lo forma los procesos internos del aprendizaje. Es indispensable que los alumnos tengan sus conocimientos claros, esto para evitar confusiones. Si hablamos de la motivación, normalmente se considera que esta va por parte del alumno hacia la materia, y más aún cuando hablamos de confianza; considero que en realidad es fundamental la participación del docente en la activación positiva de esa motivación y confianza de la cual, algunas veces, los alumnos requieren (Gagné, 1997).

Por su parte, Dewey, psicólogo y pedagogo estadounidense, menciona en su libro Democracy and education que el ambiente influye de gran manera en nuestra existencia, de modo que influye para el éxito o el fracaso de cada

Para Dewey, el maestro es un guía, es quien encamina al alumno, lo orienta. Para comprender esto, en otra de sus obras, titulada La opinión pública y sus problemas dice:

El árbol se yergue sólo cuando está enraizado en el suelo; vive o muere en función de su conexión con la luz del Sol, el aire y el agua. En ese caso, el árbol también es un conjunto de partes de un todo que interactúan; iconstituye el árbol un todo singular en mayor en medida que sus células? Una piedra se mueve, aparentemente sola. Pero la mueve otra cosa y la trayectoria que sigue depende no sólo del impulso inicial, sino del viento y la gravedad. La golpea el martillo, y lo que antes fue una piedra se convierte en un montón de partículas polvorientas. El químico manipula un gramo de polvo, e inmediatamente éste desaparece en un conjunto de moléculas, átomos y electrones. ¿Y luego? ¿Hemos alcanzado ahora un individuo solo, aunque no solitario? ¿O, quizá, el electrón, para actuar de modo singular y unitario, depende de sus conexiones, igual que lo hacia la piedra con que empezamos? ¿Es su acción también una función de algún contexto más integrador e interactivo? (Dewey, 2004, p.158).

El PEA no se puede resumir en una sola teoría, y de ninguna manera se puede decir que debemos seguir un solo camino. Existen diversas formas de enseñar y aprender. Así como cada ser humano es distinto, así son nuestras formas de aprender y así deben ser las formas de enseñar. Todo debe adecuarse a las necesidades y oportunidades que se tengan. 


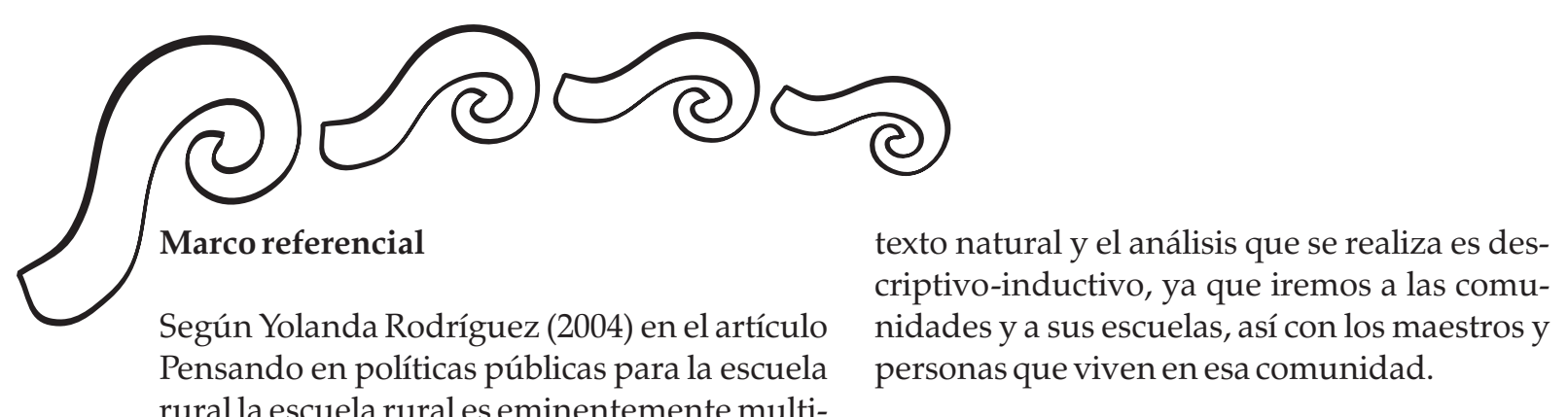
rural la escuela rural es eminentemente multigrado; estas escuelas se ubican en las zonas más apartadas del territorio y atienden mayormente a las poblaciones rurales, indígenas, bilingües y pobres, la escuela rural aunado a la pobreza de las familias y de los entornos educativos de los niños y niñas en las áreas rurales, convergen en los rendimientos negativos del sistema escolar.

De acuerdo a la investigación de Antonio Bustos Jiménez (2007) en el artículo Enseñar en la escuela rural aprendiendo a hacerlo. Evolución de la identidad profesional en las aulas multigrado menciona que el docente de escuela rural experimenta una evolución en sus sensaciones y actitudes respecto a su situación profesional. Reproduce un discurso diferente sobre las dificultades que entraña la docencia en centros rurales si se atiende a los momentos de la vida profesional en los que se producen sus valoraciones. El eje temporal antes-después se repite en casi todas las alusiones que realiza a la adaptación sufrida en el puesto de trabajo. Tiene en cuenta sus miedos, impotencias o desconciertos. El patrón al que se hace referencia está cimentado en una fase inicial alimentada por la ansiedad y una fase posterior de complacencia en la labor.

\section{Metodología}

\section{Enfoque}

El enfoque de la investigación es cualitativo ya que el proceso es flexible, porque nos adecuaremos a los hechos que acontecen, holista porque tomamos en cuenta distintos enfoques no solo uno, se establece un supuesto que va cambiando conforme los hechos, es subjetivo-objetiva y con un enfoque humanista porque trabajamos y estamos en contexto de desarrollo humano, se realiza en un con-

\section{Alcance}

El alcance de nuestra investigación es de tipo descriptivo ya que unos de los objetivos es describir las situaciones o hechos en los que nos encontramos inmersos y tratar de explicar cómo es la relación interpersonal entre docente-alumno, cuáles son las estrategias de enseñanza que utilizan los docentes y qué tanta flexibilidad los docentes dan a los contenidos para adecuarlos a las condiciones y necesidades que presentan los alumnos, especificando también las características de la comunidad y personas que van a hacer observadas.

\section{Diseño}

El diseño de la investigación es no experimental de tipo transversal.

No experimental porque se realiza sin manipular las variables; estas variables son las estrategias de enseñanza que utilizan los docentes y la misma práctica docente, así como la calidad del aprendizaje de los alumnos. En este diseño sólo es observar los fenómenos como la relación interpersonal entre docente-alumno, las estrategias de enseñanza que utilizan los docentes y la flexibilidad que ellos les dan a los contenidos para adecuarlos a las condiciones y necesidades que presentan los alumnos tal y como se dan en su contexto natural, para después poder analizarlos.

Transversal porque se recolectan los datos de un solo momento y en un tiempo único. $\mathrm{La}$ investigación se realizará del 22 al 25 de noviembre de 2011 en Molango y comunidades aledañas. A su vez es transversal descriptivo porque detalla y analiza los hechos que manifiestan las variables antes mencionadas. 


\section{Supuesto}

Suponemos que en las comunidades aledañas de Molango la calidad de aprendizaje que reciben los alumnos se ve afectada por el uso inadecuado de estrategias que los docentes aplican dentro del contexto educativo.

\section{Población}

Trabajaremos con niños de sexto grado, alrededor de los once, doce o trece años; y de acuerdo con lo que menciona Piaget acerca de esta edad es que se encuentran en la etapa de las Operaciones Formales, los niños de primaria razonan lógicamente, pero sólo en lo tocante a personas, lugares y cosas tangibles y concretas (s.a. : 115).

Esta etapa de las operaciones formales va desde los 11 a los 15 años de edad, donde los jóvenes son capaces de pensar en términos más abstractos, pueden formular hipótesis, probarlas mentalmente y aceptarlas o rechazarlas de acuerdo con el resultado de esos experimentos mentales, de esta forma son capaces de ir más allá de aquí y el ahora para entender las cosas en términos de causa y efecto, considerar posibilidades y realidades; y desarrollas y usar reglas, principios y teorías generales (Rice,1997:370).

Trabajaremos también con docentes de las distintas escuelas aledañas a la ciudad de Molango, como son Pemuxtitla, Ixmolintla, Tenango y Chalma porque con ellos se harán diferentes actividades con fines a la investigación, además de que nos ayudara a reconocer el objetivo del problema de esta misma. Las poblaciones son distintas porque algunas comunidades no tienen los mismos recursos y las mismas posibilidades económicas, ya que podremos encontrar desde casas realizadas de barro, ladrillos y lamina con un espacio reducido de hasta dos recamaras para 6 integrantes de la familia siendo hombres y mujeres, hasta casas echas de cemento concreto, tabique e incluso con techos sin lamina y de dos pisos.
La muestra que es adecuada para la investigación es la no probabilística porque la realizaremos con alumnos y docentes para que sea un trabajo íntegro en la calidad de aprendizaje y este pueda ser significativo al aplicarlo en la vida cotidiana.

\section{Resultados}

\section{Entrevistas de alumnos}

A los alumnos de las escuelas primarias a las que tuvimos acceso en Molango se les realizó una pequeña entrevista con el fin de conocer la forma en que sus maestros trabajan con ellos y se obtuvieron las siguientes respuestas:

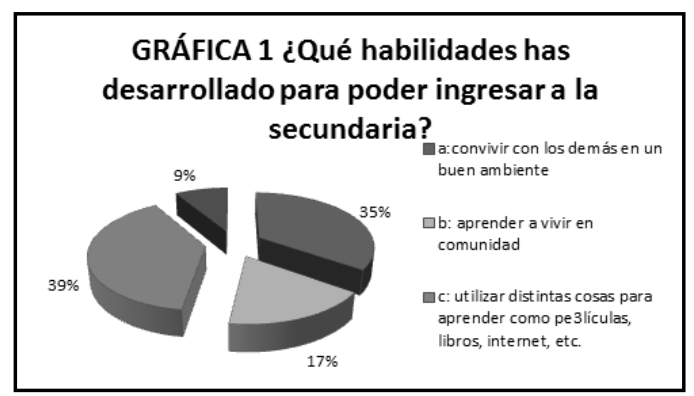

Fuente: cálculos propios con base en las entrevistas aplicadas en las escuelas primarias de las comunidades aledañas a Molango.

La gráfica indica que las opciones con a y c con $35 \%$ y $39 \%$ respectivamente, lo que indica que consideran estar mejor en la convivencia con los demás y que han aprendido que hay muchas formas en que pueden aprender.

Tal como Dewey (2004). y Gagné (1973) mencionan, los niños confían en sus maestros y en que han aprendido a utilizar distintos medios para aprender, esto de alguna manera, hace que los niños se sientan bien en su comunidad, se sienten en confianza de tener los conocimientos suficientes para ingresar a la secundaria.

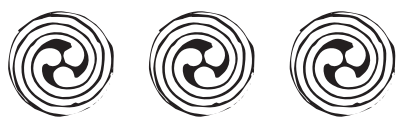




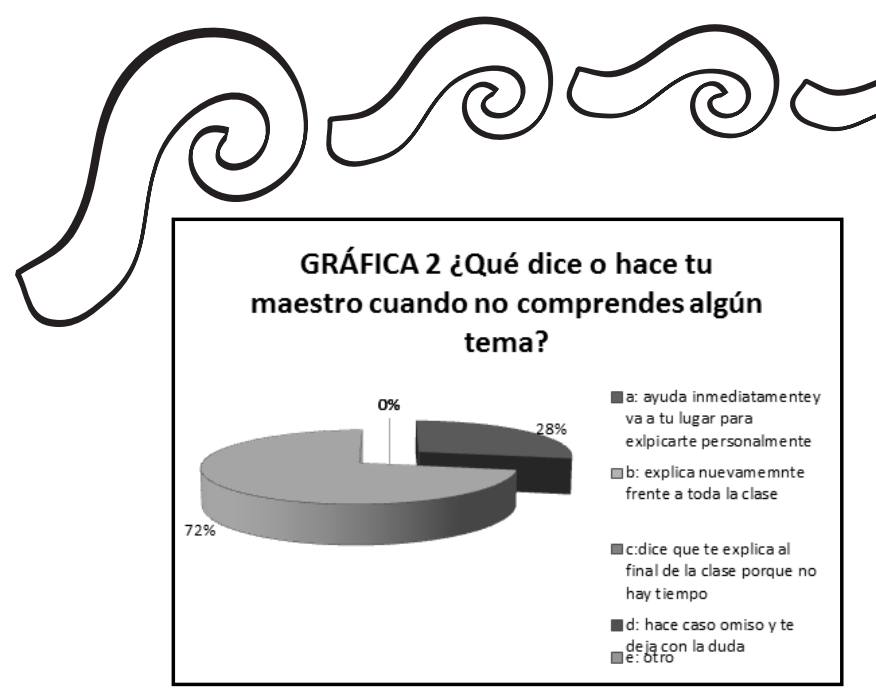

Fuente: cálculos propios con base en las entrevistas aplicadas en las escuelas primarias de las comunidades aledañas a Molango.

La gráfica dos presenta una $72 \%$ de selección en el inciso " $b$ ", el cual decía que el maestro explicaba nuevamente frente a toda la clase y en segundo lugar el inciso "a" con un $28 \%$ que se refiere a que el maestro acude al lugar del alumno a explicarle. Consideramos que nadie escogió otra opción porque sus maestros están al tanto de ellos y de su aprendizaje, esto es, los maestros tienen interés en que los niños aprendan.

Schmelkes (2001) mencionaba que los docentes deben asegurar el buen aprendizaje de los alumnos y las respuestas que se obtuvieron reflejan que los alumnos mantienen un acercamiento con ellos y se puede suponer que los niños aprenden mejor al tener un mayor contacto con el maestro en la solución de dudas.

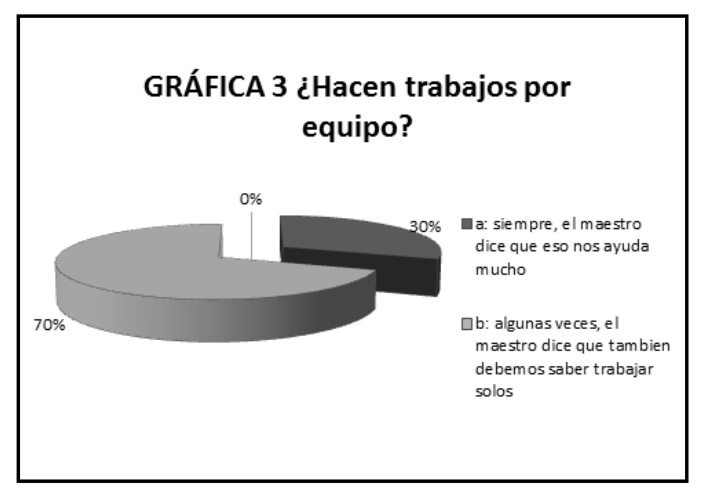

Fuente: cálculos propios con base en las entrevistas aplicadas en las escuelas primarias de las comunidades aledañas a Molango.
La gráfica 3 tenía solo tres opciones. La más elegida fue la opción b con un $70 \%$ esta se refiere a que algunas veces, el maestro los forma por equipos y nadie respondió que los maestros no forman equipos de trabajo.

Como Piaget (2003) menciona, aplicar estrategias como estas para los alumnos es muy bueno ya que pueden asociar el aprendizaje de una manera más rápida y significativa.

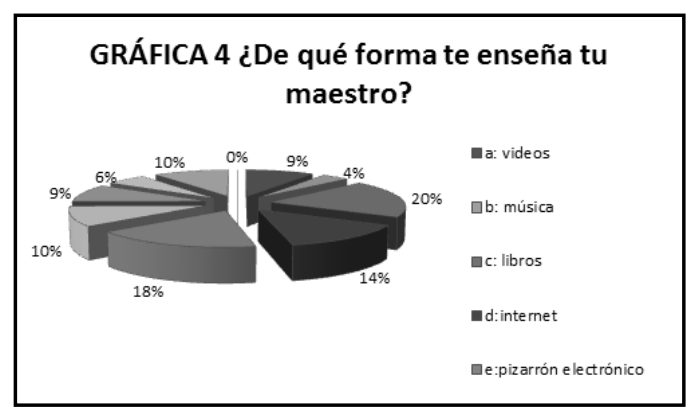

En la gráfica cuatro, las opciones que se les dieron a los alumnos eran muy variadas, pero las que fueron mayoría son con un $20 \%$ internet, con $18 \%$ pizarrón electrónico y con $14 \%$ el internet.

Piaget (2003) mencionaba que el uso de distintas estrategias era favorecedor para los alumnos, los resultados indican que los docentes utilizan distintas estrategias para la enseñanza y los alumnos, al ser entrevistados se pudo observar que mencionaban las respuestas que elegían con un tono de voz más alto lo que significaba que eso les gustaba en verdad.

De igual manera, Ausubel (1983) mencionaba que los conocimientos previos eran fundamentales para aprender conocimientos nuevos, las diferentes estrategias como videos, películas predisponen al alumno para adquirir conocimientos nuevos al terminar esas actividades.

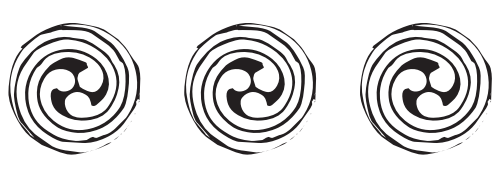




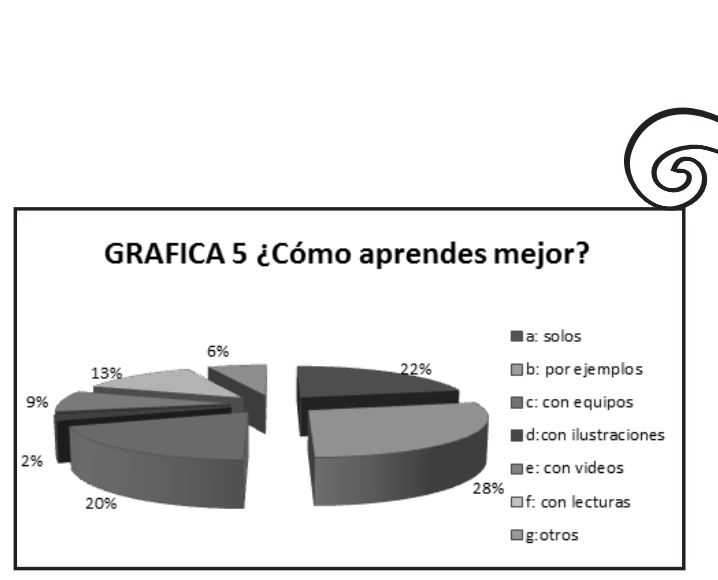

La gráfica 5 presenta la manera en que los alumnos consideran que aprenden mejor. Las respuestas que eligieron más fueron los primeros tres incisos, el b con $28 \%$, el a con $22 \%$ y elccon $20 \%$.

Lo que podemos inferir es que los alumnos obtienen mejores aprendizajes trabajando en equipos, en segundo lugar "solos" y en tercer lugar con ejemplos. Retomemos a Piaget (2001) que indica que el aprendizaje mejora con estrategias como estas, todos es mejor para los alumnos así, ellos al contestar se mostraban confiados de sus respuestas, es decir, decían sus respuestas con un tono de seguridad, además de dar respuesta inmediata.

La última pregunta que hicimos era abierta, con ella buscábamos conocer la forma en que los niños quería aprender en sus aulas, la mayoría de las respuestas que obtuvimos hablaban acerca de hacer uso del internet, uso de películas, obras teatrales, tener vivencias con el conocimiento, utilizar Enciclomedia, hacer lecturas y que los maestros les expliquen mejor.

Las vivencias remiten a la idea de Ausubel de conocimientos previos, el uso de distintos medios visuales nos remite a Piaget, en fin, los alumnos mencionaron la forma en que ellos creen que aprenden mejor y cómo les gustaría aprender.

\section{Entrevistas de docentes}

A los docentes de las escuelas primarias a las que tuvimos acceso en las comunidades de
Molango se les realizó una entrevista con el fin de conocer las estrategias que utilizan dentro del aula y la forma en que manejan el aprendizaje con los alumnos en el cual se obtuvieron las siguientes respuestas que se encuentran gráficos.

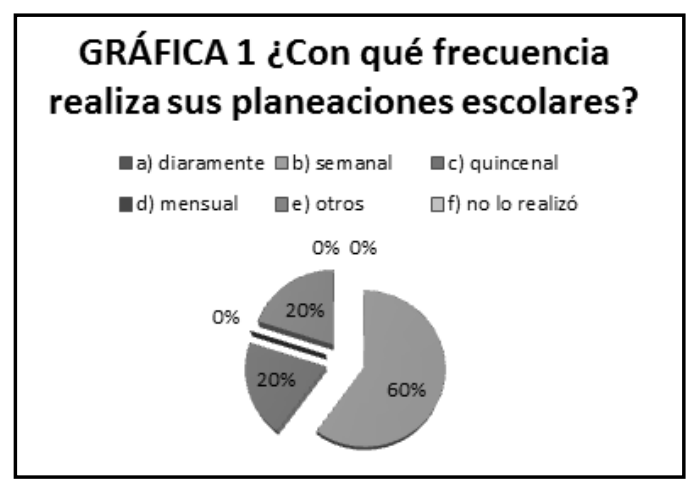

Fuente: Cálculos propios con base en las entrevistas aplicadas en las escuelas primarias de las comunidades aledañas a Molango.

En la gráfica 1 nos presenta que el $60 \%$ de los docentes realizan sus poblaciones de manera semanal, y el otro $40 \%$ corresponde a planeaciones quincenales y al tiempo que tengan los docentes para realizarla o a la modificación que se necesite hacer de acuerdo a las necesidades.

Gagné (1973) nos mencionaba que para elegir una herramienta o técnica al exponer un tema debemos considerar el mensaje que queremos dar, las personas a quien va dirigido y el mismo contexto donde se da la clase, es por eso que algunos docentes tienen que ir modificando su planeación a lo largo del curso, para ajustarse a los factores ya dichos.

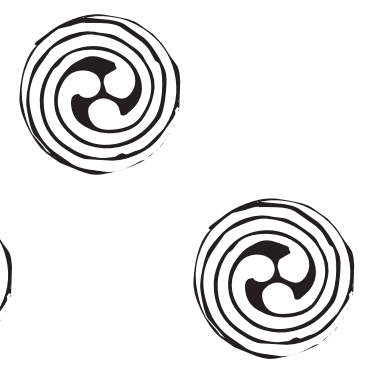




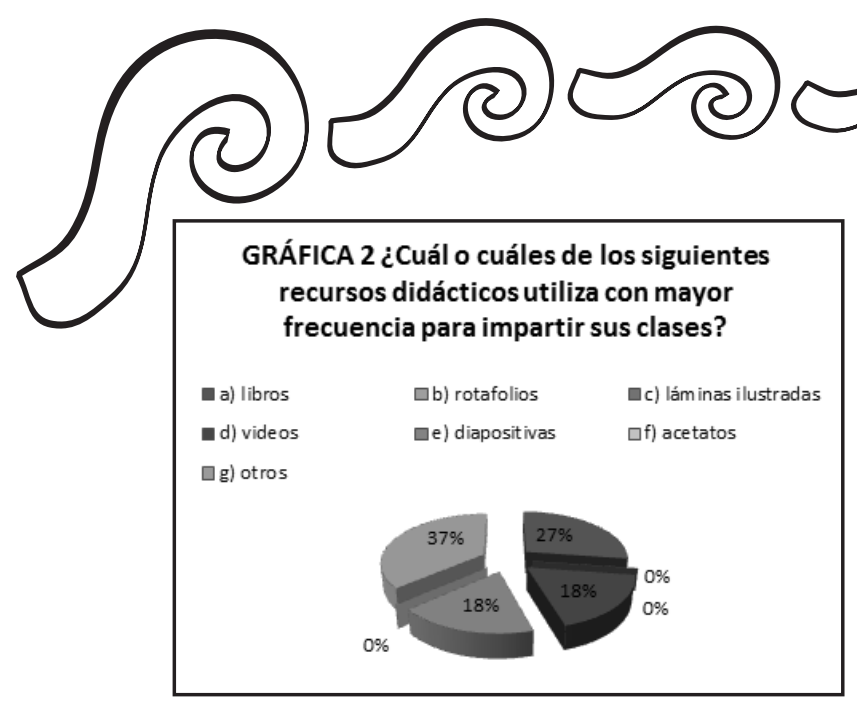

Fuente: cálculos propios con base en las entrevistas aplicadas en las escuelas primarias de las comunidades aledañas a Molango.

En la gráfica 2 podemos encontrar los resultados respecto a los recursos que más se utilizan en las comunidades visitadas: fotos, revistas, Enciclomedia, narración que se presenta en la opción de otros con u porcentaje del $37 \%$ siendo este el inciso $g$, después podemos notar que el recurso que más se utiliza son los libros dando un porcentaje de $27 \%$ en el inciso a, y el $36 \%$ corresponde a los videos y las diapositivas.

De esta manera Ausubel (1983) da a entender que el aprendizaje significativo hace un presupuesto de que el alumno pone de manifiesto una actitud de aprendizaje significativo (disposición para relacionar sustancialmente el nuevo material con su estructura cognoscitiva), así como también, que el material que aprende es sustancialmente significativo para él, por lo que es importante tener los recursos para poder llegar a este tipo de aprendizaje.

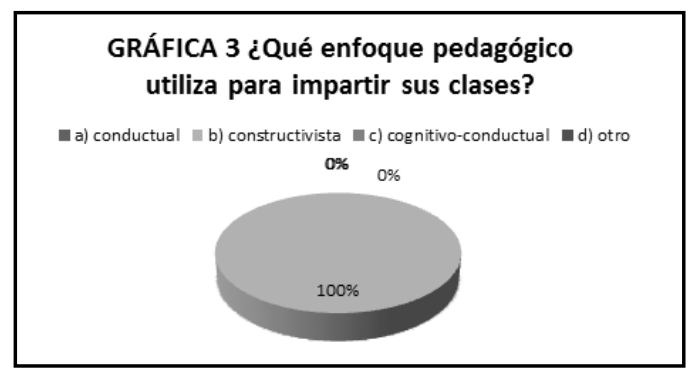

Fuente: cálculos propios con base en las entrevistas aplicadas en las escuelas primarias de las comunidades aledañas a Molango.
En la gráfica 3 se observa que todos los docentes entrevistados respondieron que utilizan en sus clases el enfoque constructivista para lograr el aprendizaje de sus alumnos, por lo que dio un $100 \%$ a esta respuesta. Respecto a esta afirmación y a lo observado, se puede citar que la mayoría de los docentes si lo utilizan pero no totalmente como lo marca dicho enfoque pedagógico, sino también lo acompañan de actividades y prácticas pedagógicas orientadas al conductismo para lograr una homogeneidad en el ritmo de aprendizaje y contenidos conceptuales del calendario escolar.

En nuestra investigación se menciona que los hechos, conceptos, procedimientos, valores y actitudes que se ensañarán deber estar relacionados básicamente con el contexto en el que viven y se desarrollan y podemos identificar que es una manera meramente constructiva de ejercer su aprendizaje por medio de estos factores.

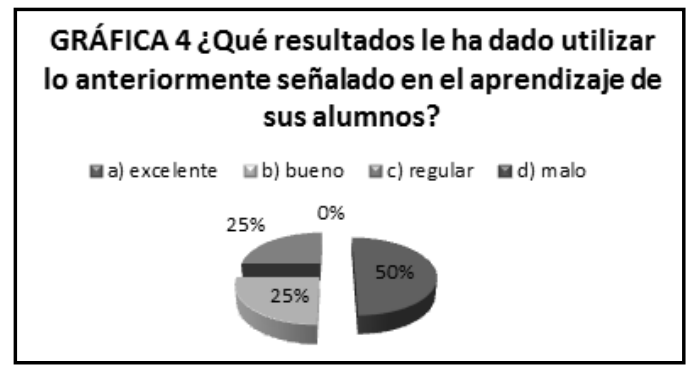

Fuente: cálculos propios con base en las entrevistas aplicadas en las escuelas primarias de las comunidades aledañas a Molango.

En la gráfica 4 la mayoría de los docentes contestó que los resultados vistos en sus alumnos al aplicar este enfoque es de nivel excelente lo que corresponde a un $50 \%$, establecido en el inciso a y el otro $50 \%$ se divide entre bueno y regular.

De acuerdo a la investigación de Antonio Bustos Jiménez (2007) en el artículo "Enseñar en la escuela rural aprendiendo a hacerlo. Evolución de la identidad profesional en las aulas multigrado" menciona que el docente de 


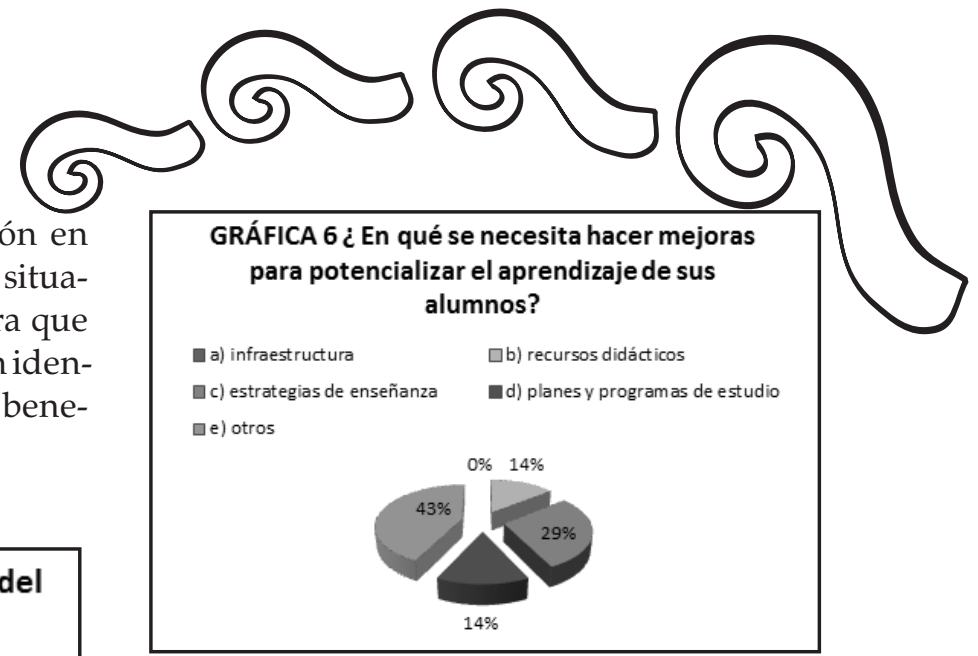

\section{GRÁFICA 5 ¿ Cómo maneja la dinámica del grupo para el trabajo a realizar?}

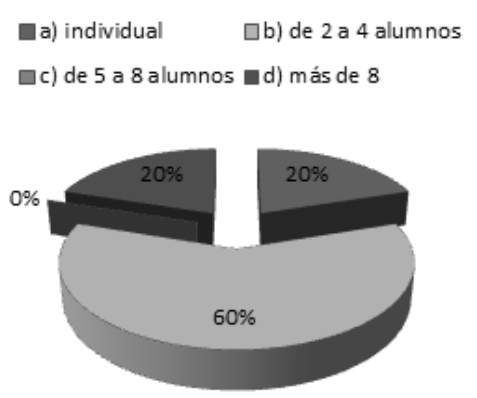

Fuente: cálculos propios con base en las entrevistas aplicadas en las escuelas primarias de las comunidades aledañas a Molango.

En la gráfica 5 podemos ver la dinámica del grupo en su mayoría de las veces se maneja de 2 a 4 alumnos por lo que nos dio un porcentaje del $60 \%$, de manera individual un $20 \%$ y más de 8 en el inciso d otro $20 \%$, por lo que también se considera importante el trabajo en equipo y de manera autónoma.

Según Schemelkes (2001), la comunidad tiene que ser capaz de saber qué esperar de la escuela. Tiene que exigirle un servicio de calidad. Debe estar dispuesta a poner lo que está de su parte para que ese servicio funcione adecuadamente, por lo que es importante ir desarrollando en el alumno una manera autónoma que sirva a lo largo de su vida y fomentar el trabajo en equipo para que las exigencias de su comunidad puedan funcionar adecuadamente.
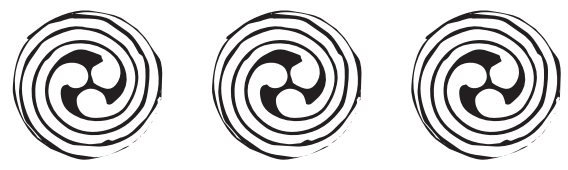

Fuente: cálculos propios con base en las entrevistas aplicadas en las escuelas primarias de las comunidades aledañas a Molango.

En la gráfica 6 lo que más se necesita mejorar dentro de las comunidades son otras opciones que no se presentan como: aplicar la reforma, estrategia técnica de guiones, la alimentación, la comunicación con los padres de familia, el internet, dándole un valor del $43 \%$, las estrategias de enseñanza con un $29 \%, 14 \%$ referente a los recursos didácticos y el $14 \%$ restante a los planes y programas de estudio.

Nuevamente Schmelkes (2001) nos menciona que la escuela podrá obtener cambios en la medida en que se fortalezca la enseñanza. La escuela tiene como cometido fundamental asegurar el aprendizaje, en ella, la enseñanza es la que lo permite. Es necesario que los docentes puedan enseñar de manera tal que los niños aprendan, por lo que es muy importante que sepan qué es lo que está exigiendo su comunidad educativa para poder mejorar.

\section{Observación de alumnos}

En el siguiente apartado se muestra el análisis cualitativo de las observaciones realizadas a los alumnos de las distintas comunidades aledañas a Molango; primeramente se encuentran las categorías y los indicadores anexando la fecha de observación, posteriormente se describen los resultados obtenidos.

De acuerdo a las observaciones realizadas del 22 al 25 de noviembre de 2011 en las comunidades de Tenango, Chalma, Ixmolintla y 


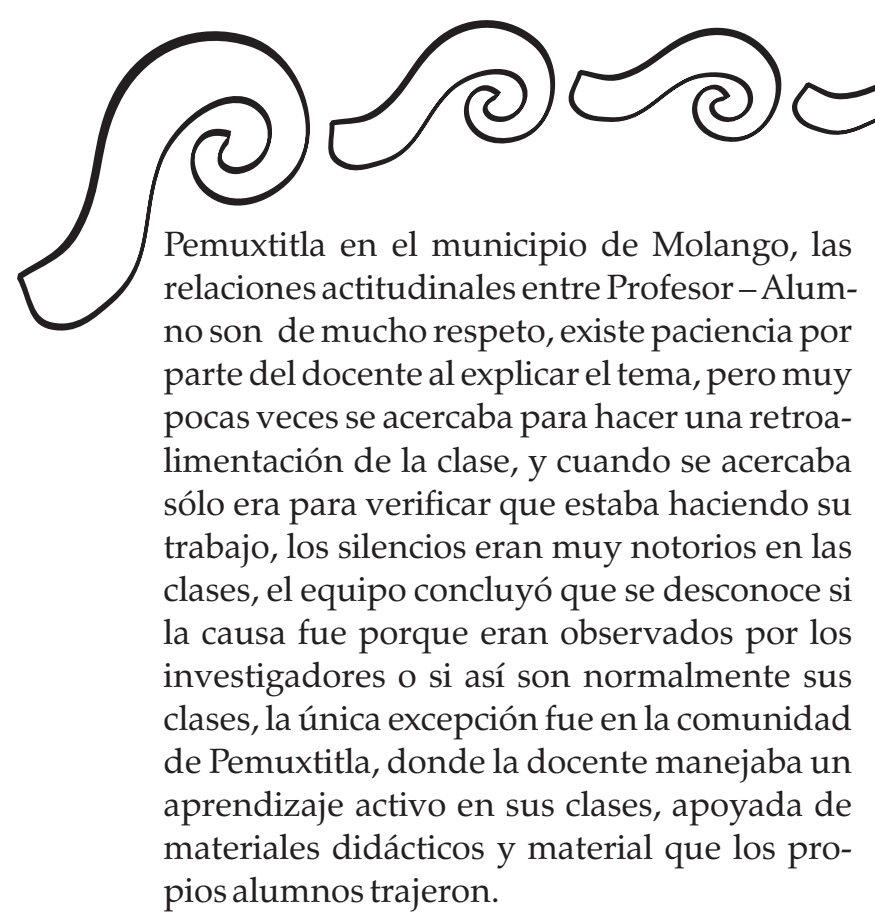

Las relaciones entre Alumno - Profesor igualmente es de mucho respeto, los alumnos están atentos a la clase, su mirada es fija cuando el docente habla, existe confianza para preguntar sus dudas ya que ellos les responden en dónde es que deben buscar las respuestas, pues expresan que con el nuevo modelo que la RIEB $^{2}$ les marca, deben propiciar que el alumno indague por su propia cuenta, sólo el docente de la comunidad de Ixmolintla permanecía observando a sus alumnos, y al momento que un alumno preguntó, su respuesta fue diferente al de las demás comunidades, le contestó "ya lo debes saber si ya lo leíste" en un tono de suposición del docente al alumno, se considera que esta actitud por parte del docente provoca que los alumnos dejen de preguntar cuando se les presente un conflicto cognitivo y se pierde la posibilidad de obtener un aprendizaje significativo en dicha clase. Esto lo menciona Ausubel muy claramente, da a entender que el aprendizaje significativo hace un presupuesto de que el alumno pone de manifiesto una actitud de aprendizaje significativo (disposición para relacionar sustancialmente el nuevo material con su estructura cognoscitiva), así como también, que el material que aprende es sustancialmente significativo para él (relacionable con su estructura de conocimiento sobre una base no arbitraria) (Ausubel, 1983: 48), así, la actitud de aprendizaje que puso de manifiesto este alumno fue coartada por el docente.

Por otra parte, los alumnos tienen libertad para tomar el material que les sea más adecuado para realizar su trabajo, desde tomar un libro, hasta imprimir una hoja, sólo se auxilian de sus docentes en caso de ser necesario.

De acuerdo a lo observado en las escuelas rurales y a lo que menciona Gagné (1997), en su obra La planificación de la enseñanza: sus principios menciona que la información que se les proporciona a los estudiantes se les puede dar a través del oído, de forma verbal, o por la vista con libros o ilustraciones, por lo tanto se analizan los siguientes estilos de aprendizaje que manejan los alumnos.

\section{Lingüística-verbal}

A pesar que el silencio entre los alumnos era el que predominaba a lo largo de la clase, los momentos en que participaban los alumnos lo hacían con un volumen de voz suave pero seguros de lo que decían, la excepción, como se mencionó anteriormente fue en la comunidad de Pemuxtitla, donde la docente propiciaba una participación activa entre sus alumnos, ya que ellos respondían en algunas ocasiones de manera acertada y recibían refuerzos verbales positivos, de lo contrario la docente sólo mencionaba que el equivocarse no era de preocuparse pues están aprendiendo pero si es necesario que pusieran más atención.

\section{Cinestésica}

En todas las comunidades se observó que la expresión corporal de los alumnos era nula, ya que la mayoría del tiempo permanecieron sentados en sus butacas, lo que fue destacable era que escribían mucho tanto en su libro de actividades como en su cuaderno, la excep-

2 Reforma Integral de la Educación Básica 


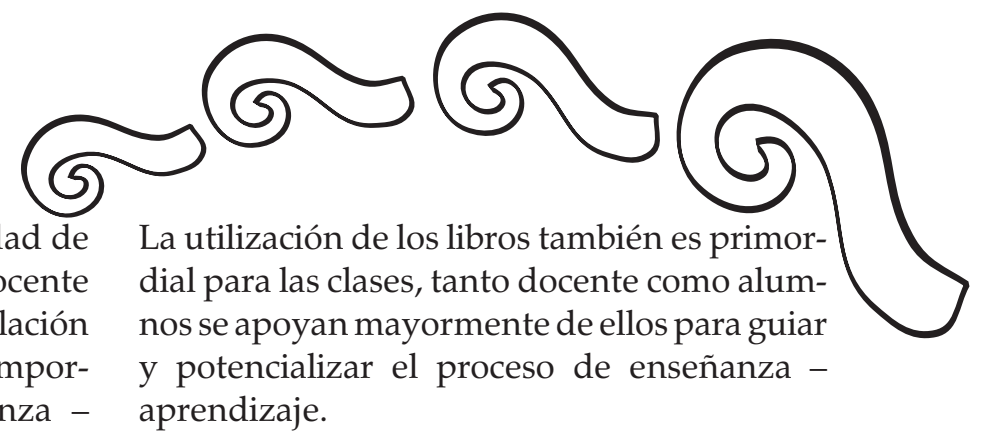

ción que se encontró fue en la comunidad de Pemuxtitla donde se observó que la docente propiciaba en sus alumnos la manipulación activa de sus materiales, esto es muy importante dentro del Proceso de Enseñanza Aprendizaje porque el alumno tiene plena libertad de observar, tocar y manipular el objeto de estudio a su comodidad, este clima de confianza que se genera en el aula también lo mencionaDewey en su libro Democracy and education"el ambiente influye de gran manera en nuestra existencia, de modo que influye para el éxito o el fracaso de cada uno de nosotros" (Dewey, 1930).

\section{Lógica-matemática}

De igual manera en todas las comunidades excepto en Pemuxtitla no se logró observar esta habilidad debido a que no aplicaba con las circunstancias de la clase, pero en la comunidad antes mencionada se observó una clase de geometría, donde los alumnos siempre tuvieron una participación activa mencionando las partes de los prismas, midieron los espacios de la caja para reproducirlas, el único detalle que hubo fue que la docente no se daba a explicar de la manera más adecuada para con los alumnos pues ellos expresaron muchas dudas para realizar la actividad, pero a pesar de ello la estrategia que empleó es muy buena.

\section{Visual-espacial}

En todas las escuelas de las diferentes comunidades que visitamos cuentan con pizarrón electrónico, cañón, computadora e impresora, los docentes saben cómo manejarla, algo muy importante para favorecer el proceso de enseñanza-aprendizaje, ya que el alumno aprende a través del oído, la vista y el tacto de acuerdo a Gagné (1997). El único inconveniente que encontramos para la utilización de dicho material electrónico fue en la comunidad de Ixmolintla pues carecían en ese momento de energía eléctrica.

Finalmente en la comunidad de Pemuxtitla es donde se observó con mayor medida un aprendizaje activo, los alumnos se encontraban en una clase de geometría, por lo tanto cada uno tenía su propio material y era libre de manipularlo, que en este caso eran cajas de diferentes tamaños, todas ellas las trajeron de su casa y por lo general eran de medicamentos, gracias a la mediación de la docente se practicó el reconocimiento de los cuerpos en el espacio, estrategia muy bien aplicada para producir un aprendizaje significativo en el alumno.

\section{Intrapersonal}

En las comunidades de Tenango e Ixmolintla se observó que las relaciones intrapersonales de los alumnos dentro del salón de clases son poco favorables para su desarrollo psicosocial, ya que permanecen la mayoría de las clase en silencio absoluto, tal vez sea la misma dinámica que el docente requiere para sus clases, pero se considera que el relacionarse entre ellos favorece y potencializa su propio proceso de enseñanza - aprendizaje, ya que se retroalimentan a través de comentarios o dudas que incluso ellos mismos expliquen a sus otros compañeros. En ocasiones algún docente llegó a callarlos, se desconoce si el docente alcanzó a escuchar la conversación entre los alumnos, pero lo que cuchicheaban era porque un alumno tenía una duda sobre un tema y su otro compañero.

A diferencia de las dos comunidades anteriores, en Chalma y Pemuxtitla la relación interpersonal entre los alumnos y el docente era muy buena ya que el mismo docente favorecía la participación y el diálogo durante la clase. Algo muy rescatable fue que un docente al 


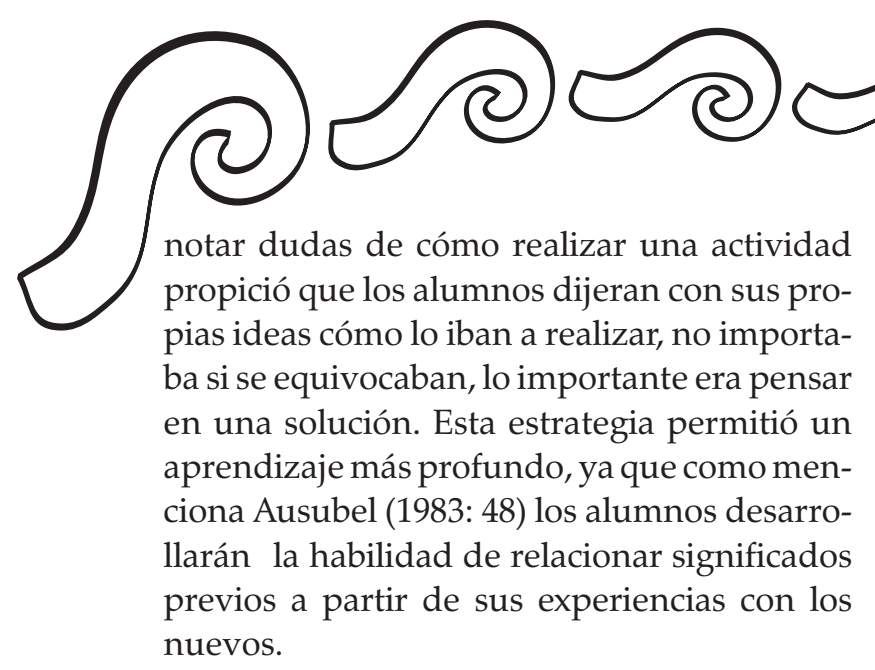

\section{Conclusiones}

Los objetivos planteados al principio de la investigación fueron logrados, debido a que se observó y sobre todo se constató cuáles son las estrategias que emplean los profesores, una de ellas y de gran utilidad, es el uso del pizarrón electrónico, pero en ocasiones llega a faltar de luz como en la comunidad de Ixmolintla y las actividades planeadas no pueden llevarse a cabo de la mejor manera. Lo más sobresaliente es que los estudiantes identifican esas estrategias con sus respectivas dificultades y en la medida de sus posibilidades tratan de ayudar al profesor.

Los recursos didácticos que se utilizan con mayor frecuencia son el papel bond y cartulinas, también se lleva al aula material físico como figuras geométricas con o sin volumen, realizan lecturas que se comentan en clase, el docente deja tarea referente a esa lectura y al día siguiente se hace la revisión de la misma, también se pudo observar que los profesores mantienen un movimiento constante por toda su aula, muy pocas veces permanecen al frente del grupo, excepto cuando se explican conceptos que requieren ser ejemplificados en el pizarrón; estos movimientos constantes permiten al docente para revisar el trabajo de sus estudiantes y auxiliar a quien tiene alguna dificultad para realizar las actividades.

De acuerdo con las preguntas de investigación que en un principio se plantearon, se respondieron de manera satisfactoria, ya que se tuvo la oportunidad de observar las estrategias que emplean los profesores en las distintas escuelas visitadas. La mayoría van encaminadas al aprendizaje significativo del alumno, porque algunos temas los realizan con actividades y materiales que los alumnos recuerden con facilidad y mediante ejemplos del tema que se trate en el momento.

Para la realización de la investigación presencial sólo se tuvo una limitante; ésta fue la lesión de tobillo que tenía una integrante del equipo, lo cual impedía caminar a un ritmo rápido y constante ya que debía de descansar por periodos de tres minutos por cada diez de caminata, por lo que se decidió que al momento de realizar el visiteo, ella acudiera a los hogares más cercanos para así evitar agravar su lesión, o se quedase en la camioneta si el camino no era muy uniforme y los demás integrantes del equipo realizarlo en los hogares más alejados. Otra limitante fue el clima lluvioso durante la visita a la comunidad de Chalma, hacía frío y había un poco de neblina en el camino, lo cual hacía un poco difícil trasladarse de manera segura debido al lodo y a las piedras mojadas. A pesar de estas dos dificultades, se pudo continuar con la investigación de manera satisfactoria.

\section{Aportaciones}

Lo que la investigación aporta es que se identificaron distintas estrategias de enseñanza que cada docente emplea en las diferentes comunidades que fuimos a visitar. Al finalizar aportaremos algunas sugerencias que podrán ayudar a las instituciones.

\section{Sugerencias}

Después de todo lo observado en las diferentes escuelas primarias de las comunidades aledañas a Molango como equipo se enumeran algunas recomendaciones que podrían ayudar tanto al docente como a la escuela a mejorar la acción educativa: 


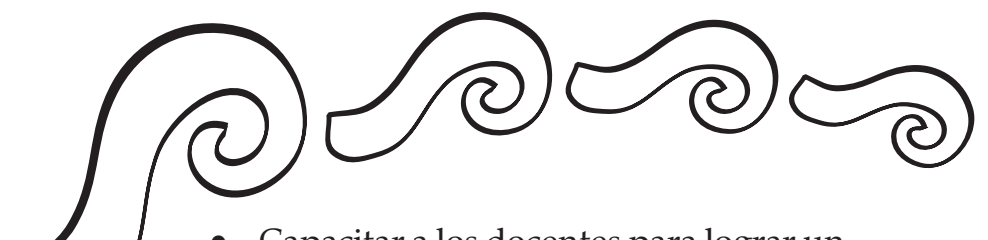

- Capacitar a los docentes para lograr un mayor acercamiento y mejorar la relación profesor-alumno, en cuanto a paciencia y tiempo para apoyar al estudiante en sus debilidades.

- Aplicar distintas estrategias de enseñanza a los alumnos facilitándoles un

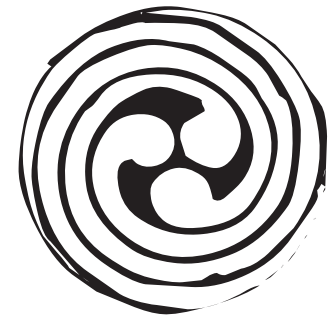
mejor aprendizaje como son la utilización de mapas conceptuales o mentales, cuadros comparativos, cuadros SQA (lo que se, lo que quiero aprender, lo que aprendí) o PNI (positivo, negativo, interesante), representaciones teatrales, y darle la importancia que tiene el narrar ejemplos de la vida cotidiana.

- Buscar realizar cursos de capacitación para los docentes donde se empleen las nuevas tecnologías, para que ellos puedan emplearlas en el salón de clases con sus alumnos.

- Encontrar la forma de que el internet llegue por lo menos a una escuela de cada comunidad para que puedan hacer uso de los nuevos recursos tecnológicos que ya poseen.

Son sugerencias que pueden servir tanto al docente como a la escuela y solo podrán llevarse a cabo si las autoridades permiten cambios, pero sobre todo que los docentes estén dispuestos a recibir talleres donde sean y crezcan como profesores y como personas además de que sean abiertos a recibir comentarios
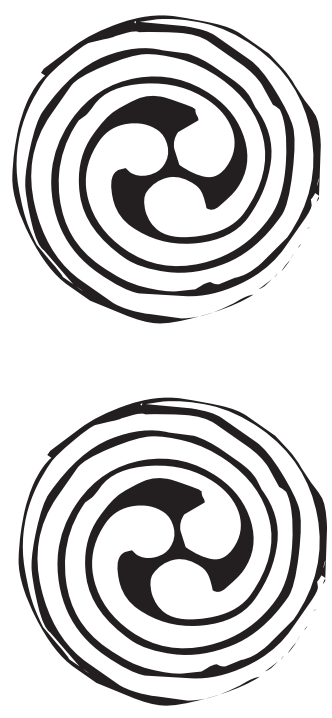
para que no se queden sólo con lo que saben.
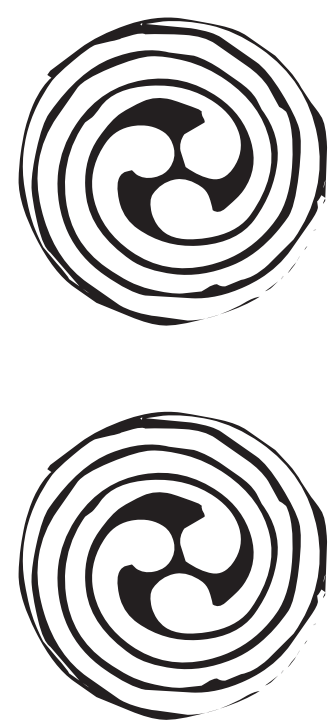


\section{Fuentes de consulta:}

Aprendizaje (2001). Real Academia Española. En Diccionario de la Lengua Española, 22a ed. Recuperado de:http://www.rae.es / draeI/Srvlt Consulta? TIPO_BUS=3\&LEMA=aprendizajeel 9 de septiembre de 2011 .

Ausubel, David, Paul (1983, reimp, 1999) Psicología educativa: un punto de vista cognoscitivo. México: Editorial Trillas.

Bustos Jiménez Antonio (2007). Enseñar en la escuela rural aprendiendo a hacerlo. Evolución de la identidad profesional en las aulas multigrado. Recuperado de: http://www.ugr.es/ recfpro/rev113COL5.pdf. Consultada el 16 de Septiembre de 2011.

Calidad (2001). Real Academia Española. En Diccionario de la Lengua Española, 22a ed. Recuperado de: http://www.rae.es /draeI/SrvltConsulta?TIPO_BUS=3\&LEMA=calidadel 9 de septiembre de 2011.

Dewey, John. (1930) Democracy and education: an introduction to the philosophy of education, New York: Editorial The Macmillan Company

Dewey, John; Trad. FilellaEscoláRoc, (1a ed.; 1a imp. 2004). La opinión pública y sus problemas, Madrid:Editorial Morata, S. L.

Educación (2001). Real Academia Española. En Diccionario de la Lengua Española, 22a ed. Recuperado de: http://www.rae.es/draeI/SrvltConsulta?TIPO_BUS=3\&LEMA=educación el9 de septiembre de 2011.

Enseñanza (2001). Real Academia Española. En Diccionario de la Lengua Española, 22a ed. Recuperado de: http://www.rae.es /draeI/SrvltConsulta?TIPO_BUS= 3\&LEMA=enseñanza el 9 de septiembre de 2011.

Estrategia (2001). Real Academia Española. En Diccionario de la Lengua Española, 22a ed. Recuperado de: http://www.rae.es /draeI/SrvltConsulta?TIPO_BUS = 3\&LEMA= estrategiael 9 de septiembre de 2011.

Gagné, Robert Mills, I. Briggs, Leslie. (1976, reimp. 1997) La planificación de la enseñanza: sus principios. México: Editorial Trillas

Martínez, Cano, Horacio (2011, octubre). Situación actual en Molango (S. Martínez, entrevistado).

Muñoz-Repiso,Mercedes; Cerdán, Jesús; Murillo, Javier; Calzón, Juan; Castro, María; Egido, Inmaculada; García, Raquel y Lucio-Villegas, Mercedes (1995).Calidad de la educación y eficacia de la escuela: Estudio sobre la gestión de los recursos educativos, Ministerio de Educación y Ciencia, Madrid.

Piaget, Jean (2001) Psicología y pedagogía, España, Barcelona:Editorial Crítica.

Piaget, Jean; Trad. Piercy Malcolm y Berlyne D.E. (2003). The Psychology of Intelligence,Londres y New York: EditorialRoutledge Classic. 
Rice, Philip. (1997). Desarrollo humano, Estudio del ciclo vital. Ed. Pearson. Recuperado de: http://books.google.com.mx/books?id=ZnHbCKUCtSUC\&pg =PA370\&dq=piaget + etapa +operaciones + formales\&hl $=$ es\&ei $=$ mOeeTsP2H8nL0QHYt4W6CQ\&sa $=$ X\&oi $=$ book_r esult\&ct $=$ result\&resnum $=10 \& v e d=0 C F s 6 A E w C Q \# v=$ onepage $\& q=\operatorname{piaget} \% 20$ etapa $\overline{\%}$ 20operaciones $\% 20$ formales $\& \mathrm{f}=$ falseel 19 de octubre de 2011 .

Rodríguez Yolanda (2004). Pensando en políticas públicas para la escuela rural. Algunas consideraciones acerca de la escuela multigrado. Recuperado de: http://www.perueduca.edu.pe/ninas-y-adolescentes-zonas rurales/archivos/ politicas_escuela_rural.pdfel 10 de septiembre de 2011.

Rural (2001). Real Academia Española. En Diccionario de la Lengua Española, 22a ed. Recuperado de: httpwww.rae.es/draeI/SrvltConsulta?TIPO_BUS=3\&LEMA=rural el 9 de septiembre de 2011.

s.s. (s.f.). Apuntes de la materia Teorías de Aprendizaje. En Teoría del Desarrollo Cognoscitivo de Piaget. p.115.

Schmelkes, Silvia (2001). Cambiar la escuela rural, Evaluación cualitativa del PARE. En revista electrónica: Ezpeleta, Justa; Weiss Eduardo et.al. (2000). Cambiar la escuela rural. Evaluación cualitativa del Programa para Abatir el Rezago Educativo. 2a . Edición revisada. México. Departamento de investigaciones Educativas del CINVESTAV.Recuperado de: http://www.red-ler.org/cambiar-escuela-rural.pdf el11 de septiembre de 2011.

Schmelkes, Sylvia (s.f.). En CONFERENCIAS MAGISTRALES, La educación rural en México. Departamento de Investigaciones Educativas, CINVESTAV, México, párrafo 9. Recuperado de: http://www.anuies.mx/servicios/d_estrategicos/libros/lib60/2.htmlel 19 de octubre de 2011.
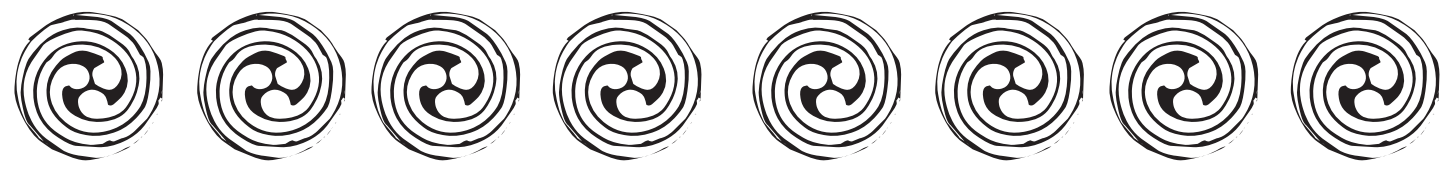
ANEXOS

Comunidad de Tenango

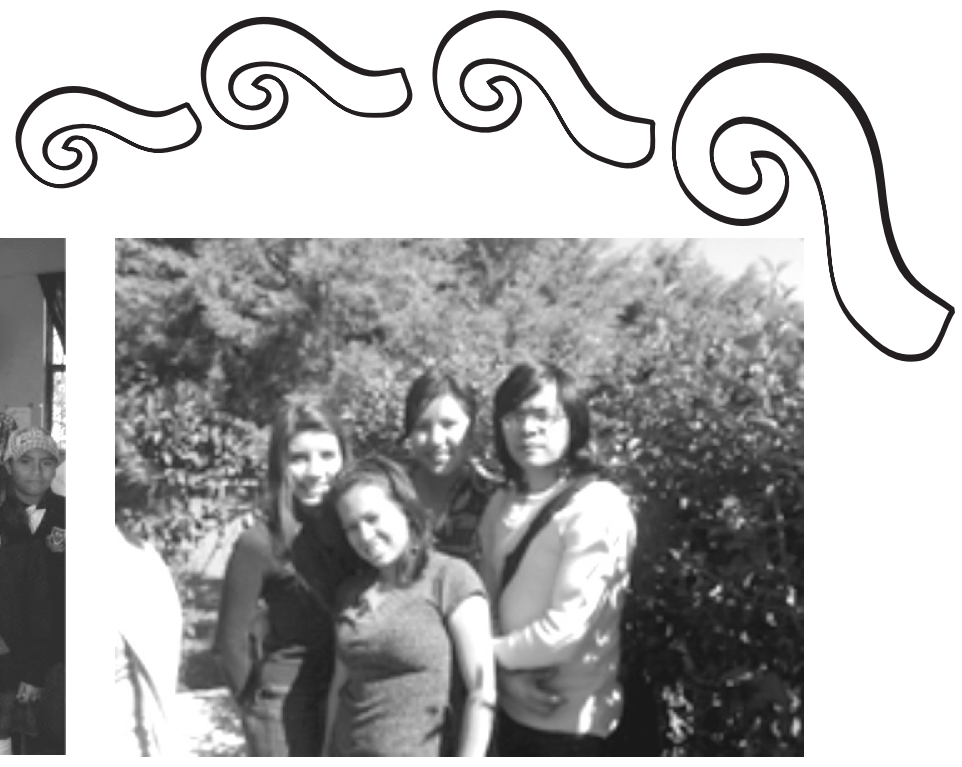

Escuela rural multigrado

"José Ma. Morelos y Pavón"

Alumnos y docente de $5^{\circ}$ y $6^{\circ}$ grado

A las afueras de la escuela

"José Ma. Morelos y Pavón"

Comunidad de Chalma

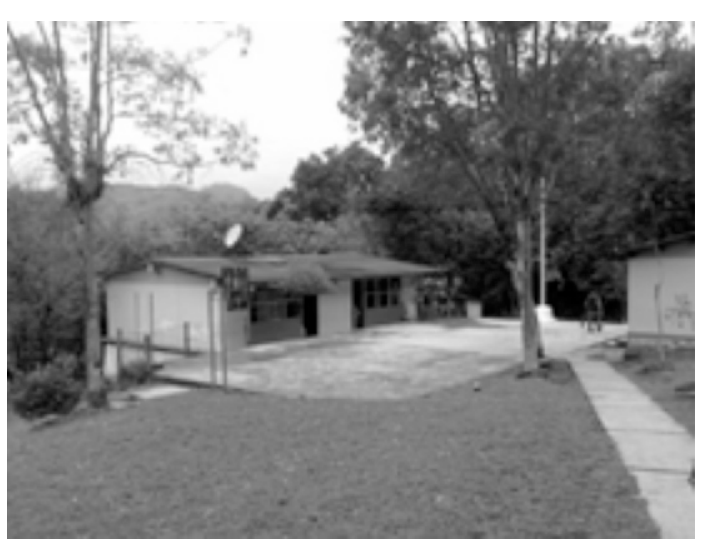

Entrada de la escuela multigrado "Nezahualcoyotl"

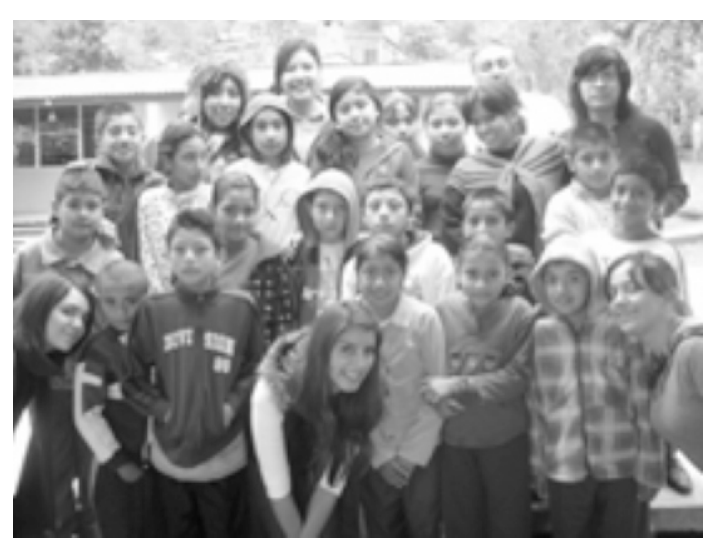

Escuela multigrado "Nezahualcoyotl" Alumnos y docente de $5^{\circ}$ y $6^{\circ}$ grado 


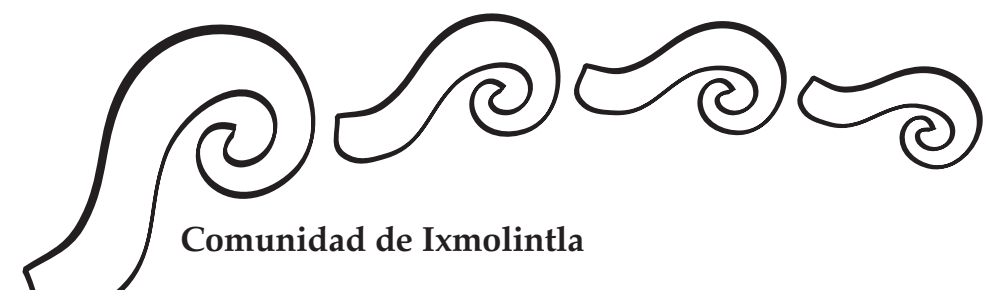

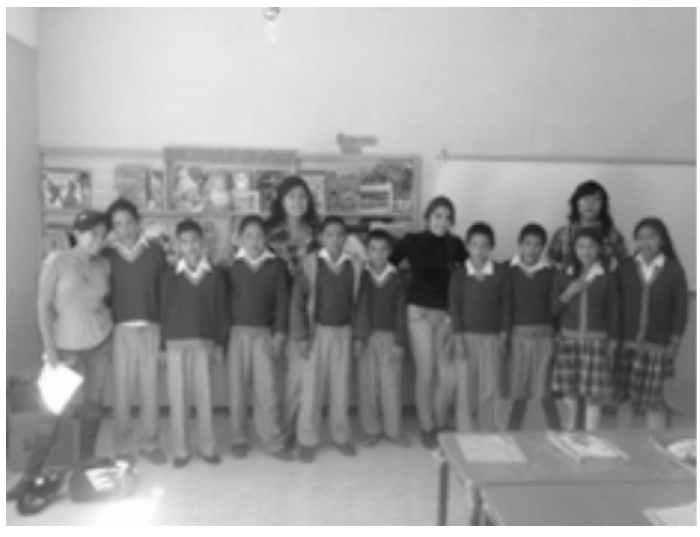

Escuela multigrado "Cecilio Hernández" Alumnos de $5^{\circ}$ y $6^{\circ}$ grado

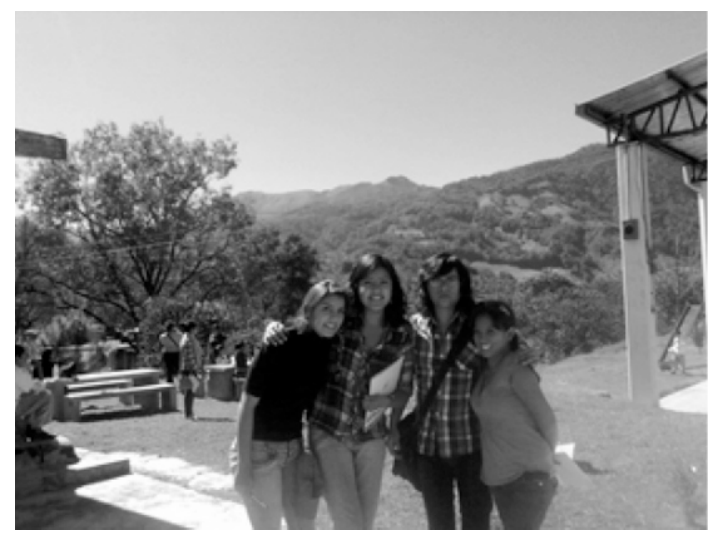

En el patio de la escuela "Cecilio Hernández"

Comunidad de Pemuxtitla

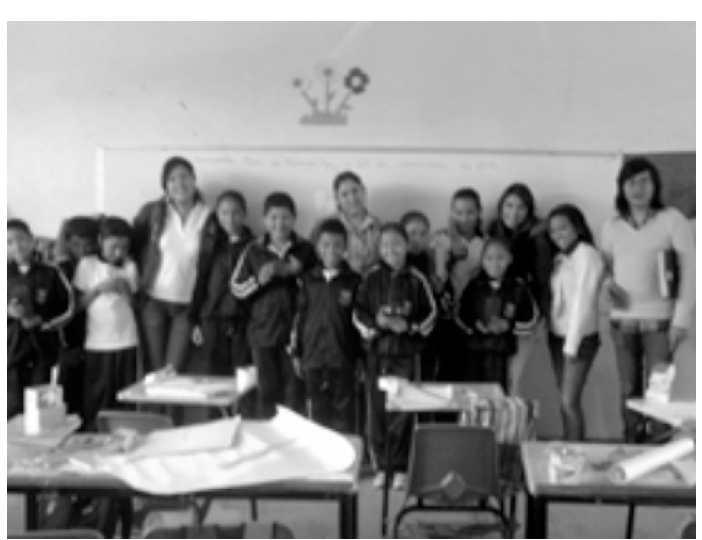

Escuela rural multigrado

"Jaime Nunó"

Alumnos y docente de $5^{\circ}$ y $6^{\circ}$ grado

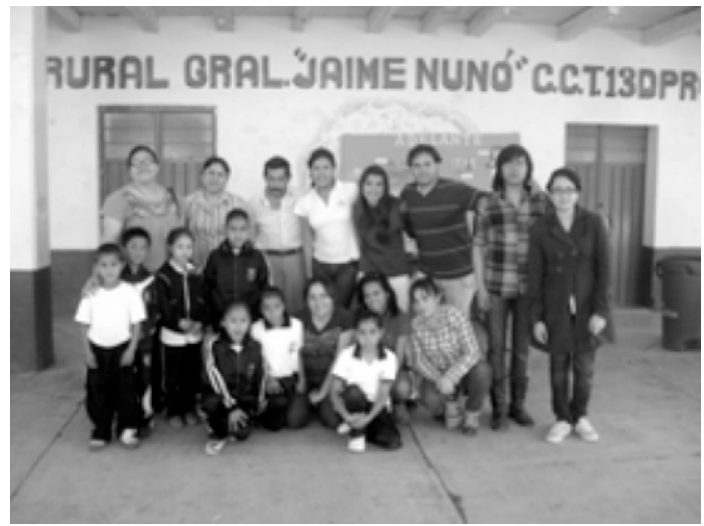

En la cancha de la escuela "Cecilio Hernández" Docentes y director 